\title{
Evaluation of a microwave desolvation system in inductively coupled plasma mass spectrometry with low acid concentration solutions
}

\author{
Juan Mora $^{a \dagger}$, Antonio Canals ${ }^{b}$, Vicente Hernandis ${ }^{b}$, Eric H. van Veen ${ }^{a}$ and \\ Margaretha T. C. de Loos-Vollebregt ${ }^{a *}$ \\ ${ }^{a}$ Laboratory of Materials Science, Delft University of Technology, Rotterdamseweg 137, NL-2628 AL Delft, The Netherlands \\ ${ }^{b}$ Department of Analytical Chemistry, University of Alicante, P.O. Box 99, 03080 Alicante, Spain
}

\begin{abstract}
The behaviour of a desolvation system based on microwave heating (termed a microwave desolvation system, MWDS) with low acid concentration solutions was evaluated in inductively coupled plasma mass spectrometry. Studies included water, sulfuric acid, perchloric acid, nitric acid and hydrochloric acid. The best performance of the MWDS was obtained at low liquid uptake rate and low acid concentrations. The analytical behaviour of the MWDS depends on the nature and composition of the solution used. In comparison with water, acid solutions provide up to four times higher ion intensities for the elements tested. In comparison with nitric and hydrochloric acid, sulfuric and perchloric acid provide higher ion intensities but also higher $\mathrm{CeO}^{+} / \mathrm{Ce}^{+}$ratios whereas $\mathrm{Ba}^{2+} / \mathrm{Ba}^{+}$ratios are lower. The limits of detection (LODs) are of the same order of magnitude for all acid solutions used, unless the specific isotope/solvent combinations suffer from spectral interference. In comparison with the conventional sample introduction (CS) without desolvation system the MWDS provides between 2 and 14 times higher ion intensities for the isotopes tested. For nitric and hydrochloric acid solutions the MWDS gives rise to lower $\mathrm{CeO}^{+} / \mathrm{Ce}^{+}$ratios and higher $\mathrm{Ba}^{2+} / \mathrm{Ba}^{+}$ratios. For sulfuric and perchloric acid these tendencies are the opposite. For the isotopes that are not subject to interference, the LODs obtained with the MWDS are up to a factor of $\mathbf{1 0}$ lower than those obtained with CS.
\end{abstract}

Keywords: Microwave desolvation; acid solution; inductively coupled plasma mass spectrometry; oxide level; doubly-charged ion level; polyatomic spectral interference

Inductively coupled plasma mass spectrometry (ICP-MS) is nowadays a widely used plasma-source mass spectrometry technique. It is a versatile and powerful technique for trace and ultratrace elemental analysis in a variety of matrices. This success mainly results from its low limits of detection, wide linear range, high scanning velocity and the possibility of obtaining isotopic information on the elements determined. Nevertheless, ICP-MS suffers from several problematic interferences. ${ }^{1,2}$ Among them, the spectral interferences caused by polyatomic ions are the largest and most difficult to avoid. These polyatomic ions are produced from atoms of the plasma gas, from entrained atmospheric gases and, mainly, from the solvent loaded into the plasma.

Considerable efforts have been made to develop alternative sample introduction methods in ICP-MS: laser ablation, ${ }^{3}$ electrothermal vaporization, ${ }^{4}$ hydride/vapour generation, ${ }^{5}$ etc. Nevertheless, solution nebulization is nowadays the most common sample introduction method for routine ICP-MS

\footnotetext{
${ }^{\dagger}$ On leave from the Department of Analytical Chemistry, University of Alicante, Alicante, Spain.
}

analysis. The degree of interference of the solvent in ICP-MS mainly depends on the amount reaching the plasma, and on its physical form (i.e., liquid or vapour) and nature (i.e., water, acids, organics, etc.). ${ }^{1,6,7}$ Acid solutions are widely used in atomic spectrometry techniques since they are often employed for solid sample digestion procedures and solution preservation. Moreover, the use of acid solutions provides several non-spectral interferences in the plasma, as has been comprehensively studied in inductively coupled plasma atomic emission spectrometry (ICP-AES). ${ }^{8,9}$ The presence of solvent influences the geometry and the excitation characteristics of the plasma and modifies the ion extraction process. ${ }^{2,10}$ These factors have a significant detrimental influence on the analytical figures of merit.

Different schemes have been applied to overcome interferences in ICP-MS. Among them, multivariate analysis is one of the simplest methods. ${ }^{11,12}$ Other attempts such as mixed gas $^{13}$ or helium ${ }^{14}$ plasmas, microwave induced plasmas ${ }^{15}$ and high-resolution instruments ${ }^{16,17}$ have also been reported. Nevertheless, the most promising way to overcome interferences in ICP-MS is through efficient solvent removal systems. ${ }^{18}$

Different desolvation systems have been employed in ICP-MS in order to reduce the amount of solvent reaching the plasma and, hence, the interferences. The simplest way consists of a cooled spray chamber. ${ }^{19,20}$ By cooling the spray chamber, the solvent in vapour form is removed from the aerosol stream, reducing the solvent load into the plasma. With these systems, a decrease in the noise level and in the $\mathrm{ArO}^{+}$signal has been reported. ${ }^{19}$ Better results have been obtained when two-unit (i.e., heater and condenser or solvent separator) desolvation systems have been employed for this purpose. ${ }^{10,16,21-27}$ With these systems oxide and hydroxide formation has been reduced ${ }^{21,22,26}$ while analyte ion intensities are sometimes improved. ${ }^{22,25}$ Also, the reduction of chlorine-induced spectral interferences such as $\mathrm{ArCl}^{+}$has been reported. ${ }^{16,21}$ With these systems, the improvement in the analytical response depends, among other instrumental factors, on the design employed. In conventional desolvation systems, the aerosol is heated by means of a conduction-convection mechanism. This heating device suffers from some drawbacks such as high memory effects and poor signal and background stability. ${ }^{28}$ Alternative systems based on ultraviolet-visible ${ }^{29}$ and infrared ${ }^{30-33}$ radiation heating have been reported.

Recently, a desolvation system based on microwave aerosol heating has been presented and evaluated in ICP-AES. ${ }^{34-36}$ With the microwave desolvation system (MWDS) and using water, improvements of about 2.5 times in the limits of detection (LODs) with respect to those obtained using a conventional desolvation system have been obtained. ${ }^{35}$ Using solutions of sulfuric and perchloric acid, the LODs obtained with the MWDS are of the same order of magnitude as those 
obtained with a commercial high-efficiency aerosol heating unit based on infrared radiation. ${ }^{36}$

The aim of the present work was to evaluate the behaviour of the MWDS in ICP-MS with low acid concentration solutions. To this end, the effect of several variables (the nebulizer gas flow rate, the liquid uptake rate and the nature and concentration of the acid) on the analytical figures of merit in ICP-MS was studied.

\section{EXPERIMENTAL}

\section{Sample introduction system}

Fig. 1 shows a schematic diagram of the MWDS set-up used. The system has been previously described. ${ }^{36}$ A pneumatic concentric-type nebulizer (Model AR-30-A3, J.E. Meinhard Associates, Santa Ana, CA, USA) attached to a single-pass spray chamber $\left(80 \mathrm{~cm}^{3}\right)$ made of Pyrex glass was used. A domestic microwave oven (Model W-2235, Balay, Zaragoza, Spain) with a nominal power of $900 \mathrm{~W}$ was employed as a heating unit. The system was connected to two Liebig condensers coupled in series. The first condenser was kept at $20^{\circ} \mathrm{C}$ and the second at $0{ }^{\circ} \mathrm{C}$. A thermostated bath was used to control the temperature of the second condenser.

In order to compare the results obtained with the MWDS, the same pneumatic concentric nebulizer employed with the MWDS attached to a standard double-pass Scott-type spray chamber constructed of polyphenylene sulfide (Perkin-Elmer SCIEX, Norwalk, CT, USA) was used. This system will henceforth be referred to as conventional sample introduction without desolvation system (CS).

Argon gas flow rate was varied from 0.60 to $1.101 \mathrm{~min}^{-1}$ by means of a single-channel mass flow controller. Liquid uptake rate was varied from 0.4 to $1.2 \mathrm{ml} \mathrm{min}^{-1}$ by means of a peristaltic pump.

\section{ICP-MS instrumentation}

Mass intensities were measured by means of an ICP-MS instrument (Model Elan 5000, Perkin-Elmer SCIEX). Table 1 lists the operating conditions employed. For the spectral interpretation, a software system based on data reduction of the measured total mass spectrum through multicomponent analysis was used. ${ }^{11}$

\section{Reagents}

Water and solutions of $\mathrm{HCl}, \mathrm{HNO}_{3}, \mathrm{HClO}_{4}$ and $\mathrm{H}_{2} \mathrm{SO}_{4}$ at different concentrations (up to $0.4 \mathrm{~mol} \mathrm{l}^{-1}$ ) were used. All the acids employed were of Suprapur quality (Merck, Darmstadt, Germany). Millipore Milli-Q water was used for dilution.

Test solutions containing $10 \mu \mathrm{g}^{-1}$ of each element were

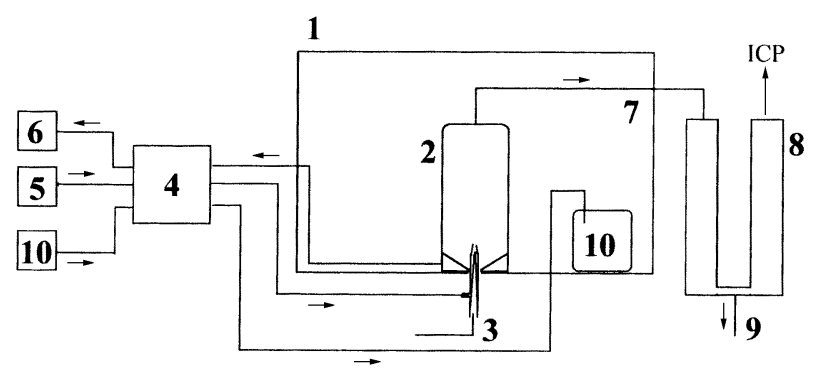

Fig. 1 Experimental set-up of the MWDS. (1) Microwave oven; (2) spray chamber; (3) nebulizer; (4) peristaltic pump; (5) sample; (6) spray chamber drains; (7) aerosol conduction; (8) condensation units; (9) condensed solvent vent; and (10) water to prevent magnetron damage.

\section{Table 1 ICP-MS operating conditions}

Plasma forward power/W

1100

Argon flow rate $/ 1 \mathrm{~min}^{-1}$.

Plasma

Auxiliary

Nebulizer

15

0.8

Variable

Sample uptake rate

Ion sampling depth from load

$\mathrm{coil} / \mathrm{mm}$

Sampling cone

Skimmer

Electron multiplier voltage/V

Scanning mode

Dwell time/s

Variable

3.0

Platinum, $1.1 \mathrm{~mm}$ aperture diameter

Platinum, $0.9 \mathrm{~mm}$ aperture diameter

$-3630$

Peak hop

Points per spectral peak

Sweeps per reading

prepared by diluting aliquots from a $1000 \mu \mathrm{g} \mathrm{ml} \mathrm{m}^{-1}$ reference solution of each element (Merck) in the appropriate solvent.

\section{RESULTS AND DISCUSSION}

\section{Characterization of the MWDS}

Effect of the nebulizer gas flow rate

Fig. 2(a) shows the effect of the nebulizer gas flow rate, $Q_{\mathrm{g}}$, on the intensity of $\mathrm{Rh}^{+}$obtained with the MWDS for water and all the acids studied. For all the solutions tested, a maximum in the $\mathrm{Rh}^{+}$signal is observed when $Q_{\mathrm{g}}$ is increased. This behaviour has also been observed for all the isotopes tested and can be explained by taking into account a series of factors, operating in opposite directions, which occur when $Q_{\mathrm{g}}$ is increased. Firstly, the aerosol generated by the nebulizer becomes finer ${ }^{37}$ and, hence, it is heated and transported more efficiently since the solvent evaporation rate for small droplets is higher. ${ }^{38}$ Consequently, $(i)$ the analyte transport efficiency increases, improving the ion intensity; and (ii) the amount of
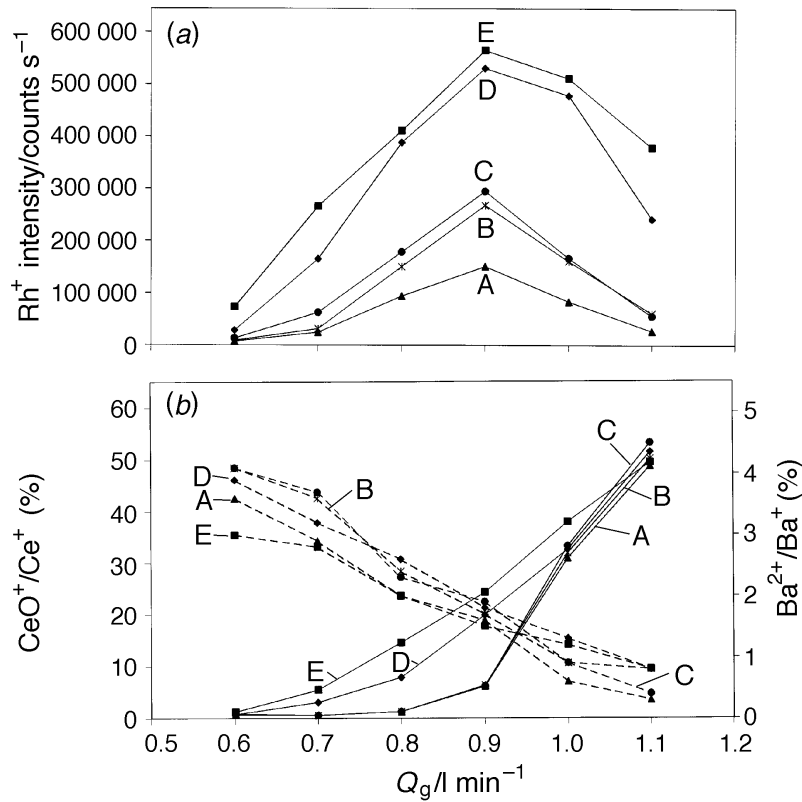

Fig. 2 Effect of the nebulizer gas flow rate, $Q_{\mathrm{g}}$, on $(a)$ the $\mathrm{Rh}^{+}$ion intensity; and $(b)$ the $\mathrm{CeO}^{+} / \mathrm{Ce}^{+}$(solid line) and $\mathrm{Ba}^{2+} / \mathrm{Ba}^{+}$(broken line) ratios for the MWDS and all the solutions tested: (A) water; (B) $\mathrm{HCl}$; (C) $\mathrm{HNO}_{3}$; (D) $\mathrm{HClO}_{4}$; and (E) $\mathrm{H}_{2} \mathrm{SO}_{4}$. Acid concentration, $0.05 \mathrm{~mol}^{-1}$. Liquid uptake rate, $Q_{1}, 0.4 \mathrm{ml} \mathrm{min}^{-1}$. Analyte concentration, $10 \mu \mathrm{g} \mathrm{1^{-1 }}$. 
solvent in vapour form in the heating unit increases, causing the solvent removal efficiency to reduce ${ }^{38}$ and, hence, increasing the amount of solvent transported to the plasma. ${ }^{35}$ The higher amount of solvent loaded has a detrimental effect on the excitation characteristics of the plasma, ${ }^{39}$ causing a reduction in the ion intensity when $Q_{\mathrm{g}}$ is increased. In addition, when $Q_{\mathrm{g}}$ is increased the zone of the maximum density of singly charged ions in the central channel of the plasma shifts in the direction of the sampler cone, causing a maximum in the signal. ${ }^{20,40}$

Fig. 2(b) shows the effect of $Q_{\mathrm{g}}$ on the $\mathrm{CeO}^{+} / \mathrm{Ce}^{+}$and $\mathrm{Ba}^{2+} / \mathrm{Ba}^{+}$ratios. It can be seen that, for all the solutions studied, the $\mathrm{CeO}^{+} / \mathrm{Ce}^{+}$ratio increases and the $\mathrm{Ba}^{2+} / \mathrm{Ba}^{+}$ ratio decreases as $Q_{\mathrm{g}}$ is increased. Similar results have been reported previously for other instruments and sample introduction systems. ${ }^{6,26,41}$ A higher amount of solvent transported to the plasma causes a higher amount of oxygen (i.e., higher oxide levels) and lower ionization efficiency of the plasma (i.e., lower doubly to singly charged ion ratio).

Table 2 shows the effect of $Q_{\mathrm{g}}$ on the $\mathrm{Rh}^{+}$intensity and on the $\mathrm{CeO}^{+} / \mathrm{Ce}^{+}$and $\mathrm{Ba}^{2+} / \mathrm{Ba}^{+}$ratios with the CS and using $\mathrm{HNO}_{3}$. As can be seen, the results obtained with the CS are similar to those described for the MWDS. These effects have also been observed for all the isotopes and solutions tested and they have been previously described for different nebulizers in ICP-MS. ${ }^{6,41,42}$

Finally, from Fig. 2 and Table 2 it can also be noticed that, for all the solutions used and both the MWDS and the CS, the highest $\mathrm{Rh}^{+}$intensities are obtained at $Q_{\mathrm{g}}=0.91 \mathrm{~min}^{-1}$. Nevertheless, the remainder of the experiments were performed at $Q_{\mathrm{g}}=0.81 \mathrm{~min}^{-1}$. This is a compromise value that provides higher signals and lower oxide levels for all the solutions studied.

\section{Effect of the liquid uptake rate}

Fig. 3(a) shows the effect of the liquid uptake rate, $Q_{1}$, on the $\mathrm{Rh}^{+}$intensity obtained with the MWDS for water and all the acids studied. Different behaviour of the $\mathrm{Rh}^{+}$signal is observed depending on the solution considered. For water, the $\mathrm{Rh}^{+}$ intensity slightly increases when $Q_{1}$ is increased whereas for all the acids studied the signal decreases. Such behaviour has been described previously ${ }^{36}$ and can be explained by taking into account two factors that take place simultaneously when $Q_{1}$ is

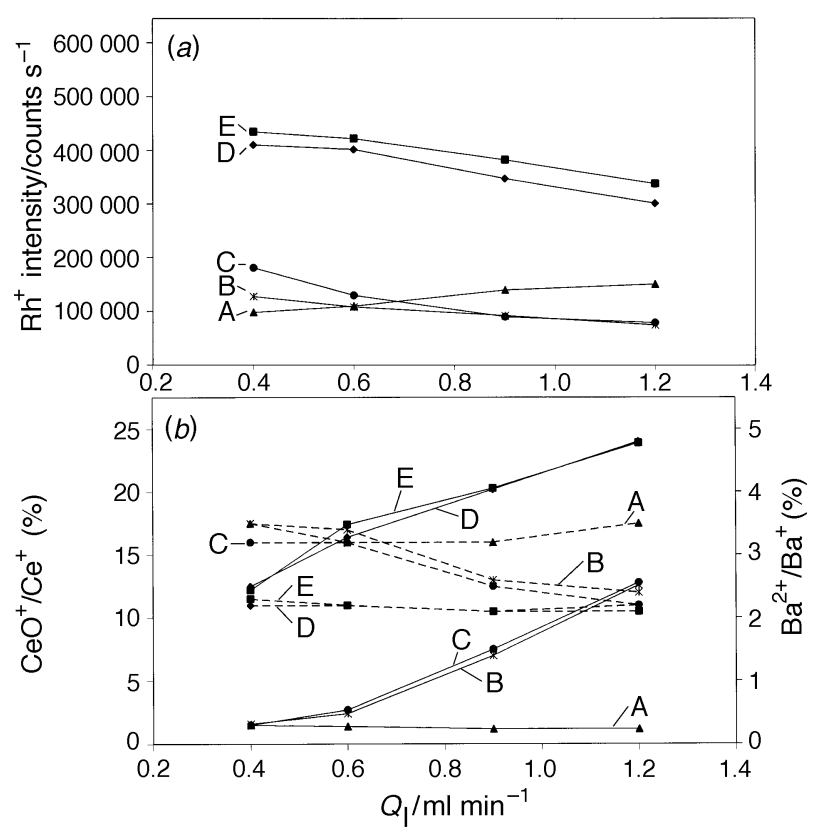

Fig. 3 Effect of the liquid uptake rate, $Q_{1}$, on: $(a)$ the $\mathrm{Rh}^{+}$ion intensity; and $(b)$ the $\mathrm{CeO}^{+} / \mathrm{Ce}^{+}$(solid line) and $\mathrm{Ba}^{2+} / \mathrm{Ba}^{+}$(broken line) ratios for the MWDS and all the solutions tested: (A) water; (B) $\mathrm{HCl}$; (C) $\mathrm{HNO}_{3}$; (D) $\mathrm{HClO}_{4}$; and (E) $\mathrm{H}_{2} \mathrm{SO}_{4}$. Acid concentration, $0.05 \mathrm{moll}^{-1}$. Gas flow rate, $Q_{\mathrm{g}}, 0.81 \mathrm{~min}^{-1}$. Analyte concentration, $10 \mu \mathrm{g}^{-1}$.

increased. First, the aerosol generated by the nebulizer becomes coarser ${ }^{37}$ thus increasing the impaction losses of the aerosol against the inner walls of the spray chamber during the heating step. The solvent transport efficiency increases and the analyte transport efficiency decreases. ${ }^{36}$ Second, the amount of aerosol and, hence, the amount of heat generated by the aerosol through microwave absorption increases. This factor increases the vaporization rate of the solvent from the droplet's surface and, thus, improves the analyte and solvent transport efficiencies. For water, in the range of $Q_{1}$ studied, the overall result of these factors produces a slight increase in the $\mathrm{Rh}^{+}$ signal [Fig. 3(a)] when $Q_{1}$ is increased. For acid solutions, since they absorb microwave radiation more efficiently than water, ${ }^{43}$

Table 2 Effect of the nebulizer gas flow rate, $Q_{\mathrm{g}}$, liquid uptake rate, $Q_{1}$, and acid concentration and nature on the $\mathrm{Rh}^{+}$signal and on the $\mathrm{CeO}^{+} / \mathrm{Ce}^{+}$and $\mathrm{Ba}^{2+} / \mathrm{Ba}^{+}$ratios with the conventional sample introduction without desolvation system, CS*

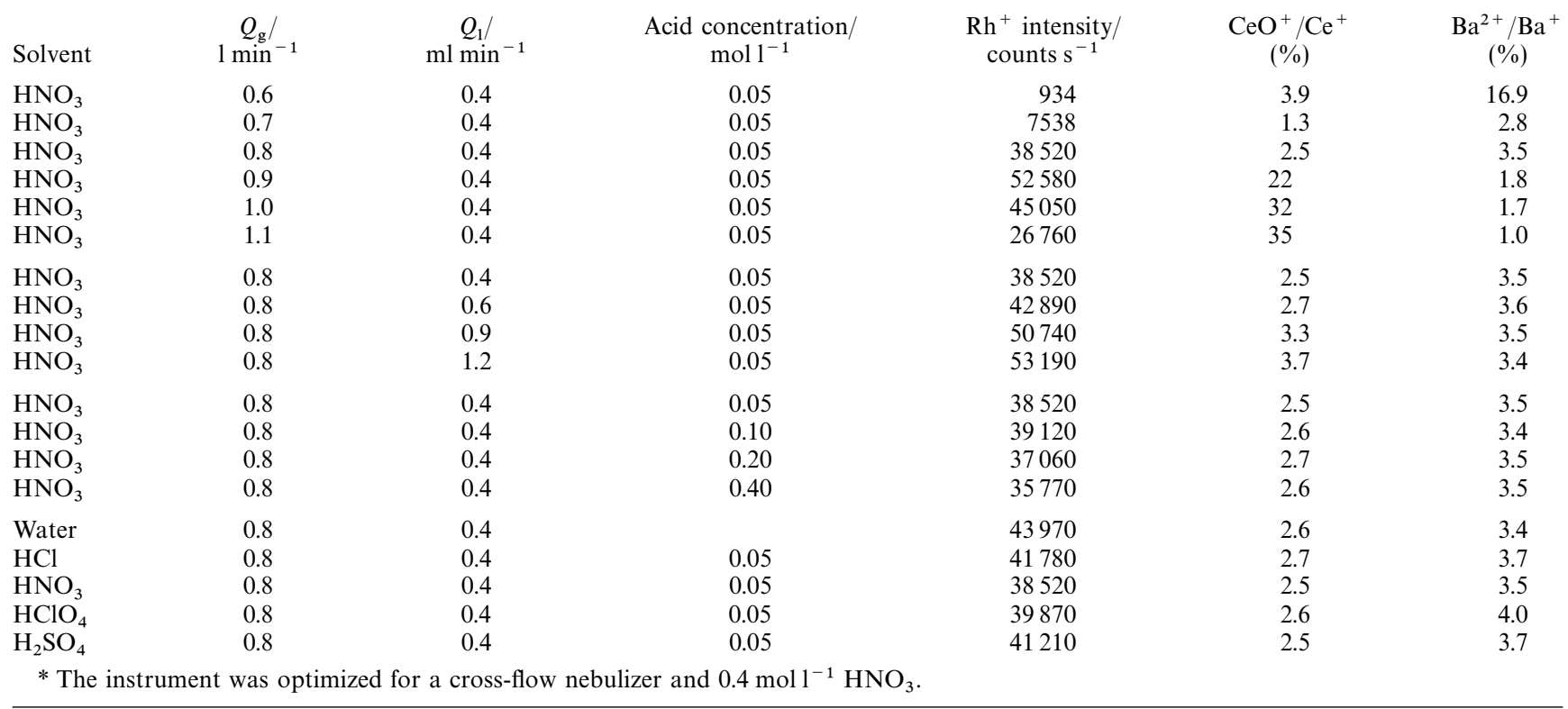


the net effect of the above-mentioned factors is a reduction in the $\mathrm{Rh}^{+}$intensity when $Q_{1}$ is increased [Fig. 3(a)].

As regards the effect of $Q_{1}$ on the $\mathrm{CeO}^{+} / \mathrm{Ce}^{+}$and $\mathrm{Ba}^{2+} / \mathrm{Ba}^{+}$ ratios obtained with the MWDS, Fig. 3(b) indicates again two different types of behaviour when $Q_{1}$ is increased. For water these ratios remain constant in the range of $Q_{1}$ studied. For acid solutions the $\mathrm{CeO}^{+} / \mathrm{Ce}^{+}$ratio rises and the $\mathrm{Ba}^{2+} / \mathrm{Ba}^{+}$ ratio slightly decreases when $Q_{1}$ is increased. Such behaviour is in agreement with the fact that with the MWDS and acid solutions, increasing $Q_{1}$ causes an increase in the amount of solvent reaching the plasma, whereas with water the variations in this parameter are much smaller. ${ }^{36,44}$

From the results shown in Table 2 it can be seen that for the CS in the range of $Q_{1}$ studied, the $\mathrm{Rh}^{+}$intensity slightly increases when $Q_{1}$ is increased. ${ }^{41}$ Table 2 also shows that the $\mathrm{CeO}^{+} / \mathrm{Ce}^{+}$ratio slightly increases whereas the $\mathrm{Ba}^{2+} / \mathrm{Ba}^{+}$ratio remains constant when $Q_{1}$ is increased.

\section{Effect of the acid concentration and solution nature}

Ion migration is one of the mechanisms of microwave absorption. ${ }^{43}$ Hence, for a solution, the ability to heat by absorption of microwave radiation depends, among other factors, on its ionic conductance. Therefore, acid solutions have a greater capacity than water to be heated by means of microwave radiation. For a given acid, the efficiency of microwave heating improves on increasing the acid concentration. Taking into account these factors, it is clear that the analytical behaviour of the MWDS will strongly depend on the nature and composition of the solvent.

Fig. 4(a) shows the effect of the acid concentration and nature on the $\mathrm{Rh}^{+}$signal. It can be seen that, for all the acids tested, when the acid concentration is increased, the $\mathrm{Rh}^{+}$ intensity rises to a maximum at concentrations of $0.05 \mathrm{~mol} \mathrm{l}^{-1}$ and then decreases. This behaviour has been previously described for $\mathrm{H}_{2} \mathrm{SO}_{4}$ and $\mathrm{HClO}_{4}{ }^{36}$ and can be explained by considering that the higher reduction in the droplet's size, which would tend to improve the transport of analyte, is counterbalanced by the higher amount of solvent in vapour form generated in the heating unit when the acid concentration

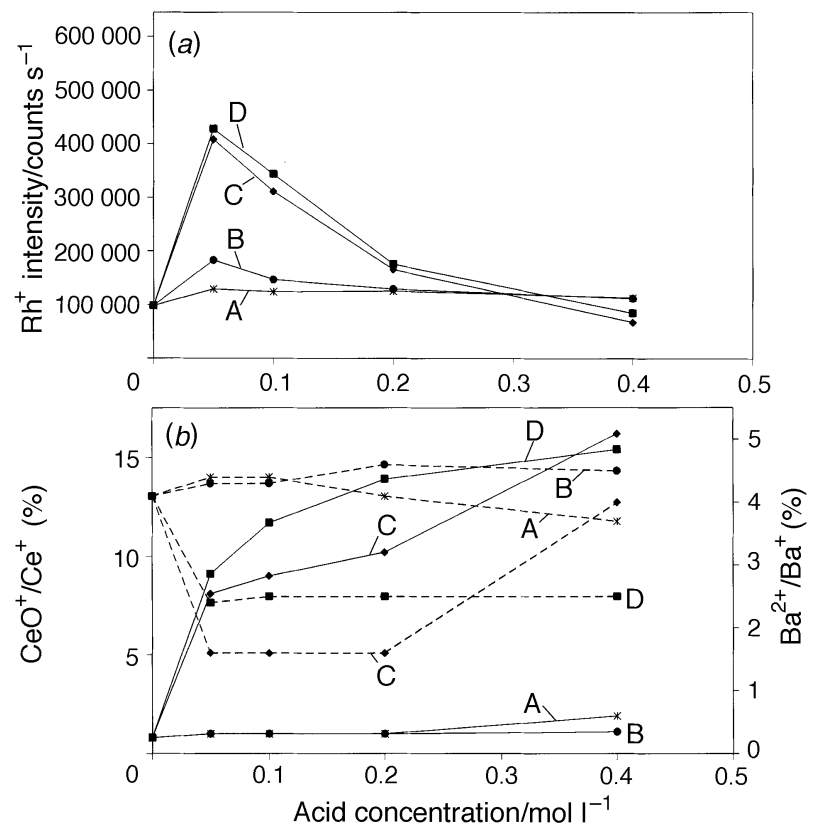

Fig. 4 Effect of the acid concentration on: $(a)$ the $\mathrm{Rh}^{+}$ion intensity; and $(b)$ the $\mathrm{CeO}^{+} / \mathrm{Ce}^{+}$(solid line) and $\mathrm{Ba}^{2+} / \mathrm{Ba}^{+}$(broken line) ratios for the MWDS and all the acids tested: (A) $\mathrm{HCl}$; (B) $\mathrm{HNO}_{3}$; (C) $\mathrm{HClO}_{4}$; and (D) $\mathrm{H}_{2} \mathrm{SO}_{4}$. Liquid uptake rate, $Q_{1}, 0.4 \mathrm{ml} \mathrm{min}{ }^{-1}$. Gas flow rate, $Q_{\mathrm{g}}, 0.81 \mathrm{~min}^{-1}$. Analyte concentration, $10 \mu \mathrm{g}{ }^{-1}$. is increased. The net result of both effects is the maximum in the ion intensity that is shown in Fig. 4(a). This maximum, which has been observed for all the isotopes tested, is more pronounced for $\mathrm{H}_{2} \mathrm{SO}_{4}$ and $\mathrm{HClO}_{4}$ than for $\mathrm{HNO}_{3}$ and $\mathrm{HCl}$.

Fig. 4(b) shows that for $\mathrm{HNO}_{3}$ and $\mathrm{HCl}$, the $\mathrm{CeO}^{+} / \mathrm{Ce}^{+}$ ratio does not change when the acid concentration changes. For $\mathrm{H}_{2} \mathrm{SO}_{4}$ and $\mathrm{HClO}_{4}$ this ratio increases when the acid concentration is increased. As regards the effect of the acid concentration on the $\mathrm{Ba}^{2+} / \mathrm{Ba}^{+}$ratio, Fig. 4(b) shows that for $\mathrm{HCl}$ and $\mathrm{HNO}_{3}$ this ratio remains constant whereas for $\mathrm{H}_{2} \mathrm{SO}_{4}$ and $\mathrm{HClO}_{4}$ it becomes lower when the acid is present. These results are in agreement with the fact that for $\mathrm{HNO}_{3}$ and $\mathrm{HCl}$, the amount of solvent reaching the plasma is almost independent of the acid concentration, ${ }^{44}$ whereas for $\mathrm{H}_{2} \mathrm{SO}_{4}$ and $\mathrm{HClO}_{4}$, the amount of solvent reaching the plasma increases when the acid concentration is increased. ${ }^{36}$

On comparing the results obtained with the different solutions studied, from Fig. 4(a) it can be concluded that acid solutions give rise to higher $\mathrm{Rh}^{+}$intensities (between 1.3 and 4.4 times higher, depending on the acid considered) than water. Fig. 4(a) also shows that, at concentrations of acid lower than $0.2 \mathrm{moll}^{-1}$, the $\mathrm{Rh}^{+}$intensities obtained for the different acids tested are in the order: $\mathrm{H}_{2} \mathrm{SO}_{4}>\mathrm{HClO}_{4}>>\mathrm{HNO}_{3}>$ $\mathrm{HCl}$.

As regards the relative influences of the acids studied on the $\mathrm{CeO}^{+} / \mathrm{Ce}^{+}$and $\mathrm{Ba}^{2+} / \mathrm{Ba}^{+}$ratios, Fig. $4(b)$ shows that $\mathrm{H}_{2} \mathrm{SO}_{4}$ and $\mathrm{HClO}_{4}$ give rise to higher $\mathrm{CeO}^{+} / \mathrm{Ce}^{+}$and lower $\mathrm{Ba}^{2+} / \mathrm{Ba}^{+}$ values than $\mathrm{HNO}_{3}$ and $\mathrm{HCl}$.

The above results indicate that $\mathrm{H}_{2} \mathrm{SO}_{4}$ and $\mathrm{HClO}_{4}$ solutions are heated more efficiently and, hence, provide higher amounts of analyte and solvent to the plasma than $\mathrm{HNO}_{3}$ and $\mathrm{HCl}^{44}$ The relative behaviour of $\mathrm{H}_{2} \mathrm{SO}_{4}$ could be related to its higher ionic conductance (this acid shows the highest $\mathrm{H}_{3} \mathrm{O}^{+}$concentration). ${ }^{36,43,45}$ Although the ionic conductance of the solutions of $\mathrm{HCl}, \mathrm{HNO}_{3}$ and $\mathrm{HClO}_{4}$ is similar, their analytical response is different [Fig. 4(a) ]. Furthermore, the drop size distributions of the aerosols generated with all these solutions are similar ${ }^{8,36,44}$ since there are no differences between their physical properties (i.e., surface tension, viscosity, etc.) at the levels of concentration studied. Therefore, the impaction losses of the aerosol against the inner walls of the spray chamber in the heating unit should be similar for all the acids studied. When attempting to explain the different analytical behaviour of the acid solutions tested, it should be taken into account that microwave radiation heating takes place by the interaction between the electrical component of the electromagnetic wave and the matter. ${ }^{43}$ It is well-known that the aerosol generation process produces charged droplets, the charge of which depends on the nature and composition of the solution from which the aerosol has been generated. ${ }^{46,47}$ The differences observed between the different microwave heating behaviour of the aerosols tested might be attributed to their different charge since, depending on its magnitude, the interaction between the microwave field and the matter would be different.

Table 2 shows that, under the experimental conditions used in this work, no effect of the acid concentration and nature on the $\mathrm{Rh}^{+}$intensity and on the $\mathrm{CeO}{ }^{+} / \mathrm{Ce}^{+}$and $\mathrm{Ba}^{2+} / \mathrm{Ba}^{+}$ratios was observed with the CS.

\section{Comparison of the analytical performance of the MWDS with that of the CS}

\section{Sensitivity}

In order to evaluate the benefits of the MWDS in ICP-MS, the ion intensities of several elements with different atomic masses were measured. The results were compared with those obtained with the CS. Results are presented in Table 3, from which it can be noticed that the ion intensities obtained with 
Table 3 Comparison of the results obtained with the MWDS and with the conventional sample introduction without desolvation system, CS*

\begin{tabular}{|c|c|c|c|c|c|c|c|c|c|c|c|}
\hline \multirow[b]{2}{*}{ Solvent } & \multicolumn{5}{|c|}{$I_{\mathrm{MWDS}} / I_{\mathrm{CS}}$} & \multicolumn{2}{|c|}{$\begin{array}{l}\text { RSD } \\
(\%)\end{array}$} & \multicolumn{2}{|c|}{$\begin{array}{c}\mathrm{CeO}^{+} / \mathrm{Ce}^{+} \\
(\%)\end{array}$} & \multicolumn{2}{|c|}{$\begin{array}{c}\mathrm{Ba}^{2+} / \mathrm{Ba}^{+} \\
(\%)\end{array}$} \\
\hline & ${ }^{24} \mathrm{Mg}^{+}$ & ${ }^{103} \mathrm{Rh}^{+}$ & ${ }^{138} \mathrm{Ba}^{+}$ & ${ }^{140} \mathrm{Ce}^{+}$ & ${ }^{208} \mathrm{~Pb}^{+}$ & MWDS & $\mathrm{CS}$ & MWDS & $\mathrm{CS}$ & MWDS & $\mathrm{CS}$ \\
\hline Water & 3.5 & 2.2 & 3.0 & 3.4 & 2.9 & $2-3$ & $1-2$ & 0.8 & 2.6 & 4.1 & 3.4 \\
\hline $\mathrm{HCl}$ & 4.1 & 2.7 & 2.9 & 3.2 & 3.1 & $2-3$ & $2-3$ & 1.0 & 2.7 & 4.4 & 3.7 \\
\hline $\mathrm{HNO}_{3}$ & 4.8 & 3.8 & 3.4 & 4.0 & 3.9 & $2-3$ & $1-2$ & 1.0 & 2.6 & 4.3 & 3.5 \\
\hline $\mathrm{HClO}_{4}$ & 10.5 & 10.2 & 14.0 & 12.5 & 14.2 & $2-5$ & $1-3$ & 9.1 & 2.6 & 2.2 & 4.0 \\
\hline $\mathrm{H}_{2} \mathrm{SO}_{4}$ & 10.3 & 10.4 & 13.8 & 12.9 & 14.4 & $2-5$ & $1-3$ & 9.1 & 2.5 & 2.4 & 3.7 \\
\hline * Acid & ration & $5 \mathrm{~mol} \mathrm{l}^{-}$ & $\mathrm{g}=0.8$ & ${ }^{-1} ; Q$ & $\mathrm{ml} \mathrm{mir}$ & & & & & & \\
\hline
\end{tabular}

the MWDS are, for all the isotopes tested, higher than those obtained with the CS. For water, $\mathrm{HCl}$ and $\mathrm{HNO}_{3}$ the ion intensities obtained with the MWDS are between 2.2 and 4.8 times higher than those obtained with the CS. When $\mathrm{H}_{2} \mathrm{SO}_{4}$ and $\mathrm{HClO}_{4}$ are used, the ion intensities obtained with the MWDS are between 10.2 and 14.4 times higher than those obtained with the CS. Improvements in the analyte ion intensity with desolvation have also been described elsewhere. ${ }^{22,25,33}$ Using a desolvation system based on the heating of the aerosol by means of a conduction-convection mechanism, an enhancement of 2-5 times has been reported. ${ }^{22}$ Higher enhancement factors have been reported with an infrared-based desolvation system (about 10 times) $^{33}$ or with an ultrasonic nebulizermembrane desolvation separation interface (between 5 and 25 times depending on the isotope tested). ${ }^{25}$

\section{Precision}

As can be seen in Table 3, the RSD of the ion intensities obtained with the CS is, for all the solutions and isotopes considered, about $1-3 \%$. With the MWDS the precision of the ion intensities depends on the solution employed. Using water, $\mathrm{HCl}$ and $\mathrm{HNO}_{3}$, the RSD values obtained for the MWDS are about 2-3\%. When $\mathrm{H}_{2} \mathrm{SO}_{4}$ and $\mathrm{HClO}_{4}$ are used, the RSD of the signal is higher with the MWDS than with the CS (2-5 and $1-3 \%$, respectively). The fast evaporation of the droplets reduces the stability of the system. ${ }^{28}$

\section{$\mathrm{CeO}^{+} / \mathrm{Ce}^{+}$and $\mathrm{Ba}^{2+} / \mathrm{Ba}^{+}$ratios}

Table 3 also shows that the $\mathrm{CeO}^{+} / \mathrm{Ce}^{+}$ratio values obtained for water, $\mathrm{HCl}$ and $\mathrm{HNO}_{3}$ and with the MWDS are between 2.6 and 3.3 times lower than those obtained with the CS. These results indicate the lower amount of solvent loaded into the plasma with the MWDS. This fact gives rise to slightly higher (1.2 times higher) values of the $\mathrm{Ba}^{2+} / \mathrm{Ba}^{+}$ratios with the MWDS than with the CS. Nevertheless, the oxide levels observed with the MWDS for these solutions are higher than those reported with other desolvation systems provided with a membrane ${ }^{25}\left(\mathrm{CeO}^{+} / \mathrm{Ce}^{+}\right.$about $\left.0.1 \%\right)$ or cryogenic ${ }^{21}$ $\left(\mathrm{CeO}^{+} / \mathrm{Ce}^{+}\right.$between 0.02 and $\left.0.05 \%\right)$ solvent removal unit. For $\mathrm{H}_{2} \mathrm{SO}_{4}$ and $\mathrm{HClO}_{4}$ and with the MWDS the $\mathrm{CeO}^{+} / \mathrm{Ce}^{+}$ ratios are higher and the $\mathrm{Ba}^{2+} / \mathrm{Ba}^{+}$ratios lower than those obtained with the CS. This is due to the high amount of solvent introduced into the plasma under these conditions.

\section{Background mass spectrum}

The behaviour of the MWDS was also evaluated by measuring the background mass spectrum for the different solutions studied. The results were compared with those obtained with the CS.

First, it is important to point out that, for all the solutions tested, higher ion signals for $\mathrm{C}$ were found with the MWDS than with the CS. Similar signal enhancements were observed for Xe and Kr. Evidently, these three species are introduced into the plasma from the argon gas. Since the argon flow rates are exactly the same for both the MWDS and the CS, these different signals can be attributed to the different plasma behaviour arising from the two sample introduction systems. In addition, for all the solutions studied, significantly higher signals for $\mathrm{Si}$ were found with the MWDS than with the CS. The higher $\mathrm{Si}$ ion intensities in the background mass spectra are probably due to the present design of the MWDS with a glass spray chamber. The heating of the sample solutions in the spray chamber will cause degradation and, hence, introduce $\mathrm{Si}$ as a contaminant species into the plasma.

Table 4 presents the intensities of the most relevant polyatomic ions detected in the background mass spectra of the MWDS relative to the intensities obtained with the CS for all the solutions tested. In all cases, two common interferences were observed with both systems. The first is the interference due to $\mathrm{ArO}^{+}$at $m / z$ 56, which overlaps the major isotope of iron. In this case, the signals obtained with both the MWDS and the CS are similar (about 340000 counts s$^{-1}$ ) for all the acid solutions with the exception of $\mathrm{HClO}_{4}$, for which the background signal is twice as high in the MWDS. The second interference observed for both systems and all the solutions studied is due to the presence of $\mathrm{ArO}^{+}$and $\mathrm{ArC}^{+}$at $m / z 52$. These ions overlap the major isotope of chromium. At this $m / z$ value an average signal of 1200 counts $^{-1}$ is observed with the CS. The polyatomic background signal obtained with the MWDS is about 3 times higher for all the solutions. For water, $\mathrm{HNO}_{3}$ and $\mathrm{H}_{2} \mathrm{SO}_{4}$, these higher signals are due to the contribution from $\mathrm{ArC}^{+}$since the contribution from $\mathrm{ArO}^{+}$is the same for both systems. This conclusion is in agreement with the higher intensities of $\mathrm{C}$ (at $m / z=12$ and 13) observed with the MWDS. For $\mathrm{HCl}$ and $\mathrm{HClO}_{4}$, contributions from $\mathrm{ClOH}^{+}$were found in addition to the other species observed at $m / z=52$ (i.e., $\mathrm{ArO}^{+}$and $\mathrm{ArC}^{+}$). The contribution from this chlorine-induced polyatomic ion at $m / z=52$ was estimated for both the MWDS and the CS. A relative contribution of about

Table 4 Relative intensities of the background at different masses*

\begin{tabular}{|c|c|c|c|c|c|c|}
\hline \multirow[b]{2}{*}{ Isotope } & \multirow[b]{2}{*}{ Interferent } & \multicolumn{5}{|c|}{$I_{\mathrm{MWDS}} / I_{\mathrm{CS}}$} \\
\hline & & Water & $\mathrm{HCl}$ & $\mathrm{HNO}_{3}$ & $\mathrm{HClO}_{4}$ & $\mathrm{H}_{2} \mathrm{SO}_{4}$ \\
\hline${ }^{48} \mathrm{Ti}^{+}$ & $\mathrm{SO}^{+}$ & & & & & 4 \\
\hline${ }^{51} \mathrm{~V}^{+}$ & $\mathrm{ClO}^{+}$ & & 1 & & 6 & \\
\hline${ }^{52} \mathrm{Cr}^{+}$ & $\underset{\mathrm{ArO}^{+}}{\mathrm{ClOH}^{+}}, \mathrm{ArC}^{+}$, & 3 & 3 & 3 & 4 & 3 \\
\hline $\begin{array}{l}{ }^{56} \mathrm{Fe}^{+} \\
{ }^{64} \mathrm{Zn}^{+}\end{array}$ & $\begin{array}{l}\mathrm{ArO}^{+} \\
\mathrm{SO}_{2}^{+}\end{array}$ & 1 & 1 & 1 & 2 & $\begin{array}{l}1 \\
3\end{array}$ \\
\hline${ }^{72} \mathrm{Ge}^{+}$ & $\underset{\mathrm{Cl}_{2}^{+}}{\mathrm{ArS}^{+}}, \mathrm{ClO}_{2}^{+}$ & & & & 5 & 6 \\
\hline $\begin{array}{l}{ }^{75} \mathrm{As}^{+} \\
{ }^{98} \mathrm{Mo}^{+}\end{array}$ & $\mathrm{ArCl}^{+}$ & & 3 & & 8 & \\
\hline $\begin{array}{l}{ }^{98} \mathrm{Mo}^{+} \\
{ }^{*} \text { Acid }\end{array}$ & $\mathrm{H}_{2} \mathrm{SO}_{4}^{+}$ & & & _ & & 0.1 \\
\hline
\end{tabular}


1 and 6 was found for $\mathrm{HCl}$ and $\mathrm{HClO}_{4}$ solutions, respectively. These factors are similar to the $\mathrm{ClO}^{+}$contributions observed for these solvents at $m / z=51$.

As regards the remainder of the interferences observed, Table 4 also shows that with $\mathrm{HCl}$ a higher signal of $\mathrm{ArCl}^{+}$ was observed with the MWDS than with the CS. When $\mathrm{H}_{2} \mathrm{SO}_{4}$ and $\mathrm{HClO}_{4}$ are used, the background ion intensities observed with the MWDS are, in general, higher than those obtained with the CS. These results are due to the higher amount of solvent that is transported to the plasma for these solutions with the MWDS. Finally, from Table 4 it can be seen that for $\mathrm{H}_{2} \mathrm{SO}_{4}$ at $m / z=98$, a signal of about 800 counts s$^{-1}$ was obtained with the CS. This signal is probably due to the presence of $\mathrm{H}_{2} \mathrm{SO}_{4}{ }^{+}$. With the MWDS no significant signal was found at this $m / z$ and, hence, the interference was reduced by a factor of 10 .

\section{Rinse-out times}

The rinse-out profiles obtained with the MWDS and with the $\mathrm{CS}$ were compared. With the MWDS, the $\mathrm{Rh}^{+}$ion intensity decreases to $0.1 \%$ of its steady-state value $75 \mathrm{~s}$ after the signal starts to decrease. This time is about $10 \mathrm{~s}$ longer than the rinse-out time required for the CS under the experimental conditions employed in this work. Similar results were reported using an infrared-based desolvation system. ${ }^{32}$

\section{Limits of detection}

LODs were calculated according to the $3 \sigma$ criterion, where $\sigma$ is the standard deviation of the blank. The $\sigma$ values were estimated using the approach described by Boumans: ${ }^{48-50}$

$$
\operatorname{RSD}=\left\{\alpha^{2}+[\beta /(Z \times \tau)]\right\}^{1 / 2}
$$

where RSD (\%) is the relative standard deviation of the signal, $Z$ is the background signal, $\tau$ is the integration time and $\alpha$ and $\beta$ are coefficients which represent the flicker noise and the shot noise, respectively. With ion counting, the value of $\beta$ is $10^{4}$. For a given instrument and sample introduction system, the value of $\alpha$ is given by the value of the RSD obtained at higher signals. Under the conditions of this work, the highest signals were obtained for $\mathrm{Rh}^{+}$and, hence, the RSD values obtained under each condition at this $m / z$ were used for $\alpha$.

For all the solutions tested, the LODs calculated for different isotopes and both the MWDS and the CS are presented in Table 5.

Firstly, Table 5 shows that for the isotopes that do not suffer from interferences due to the presence of solvent in the plasma, the LODs obtained with the MWDS are of the same order of magnitude irrespective of the solution employed. Hence, the higher sensitivities obtained with the MWDS for $\mathrm{H}_{2} \mathrm{SO}_{4}$ and $\mathrm{HClO}_{4}$ compared with those obtained for water, $\mathrm{HCl}$ and $\mathrm{HNO}_{3}$ (Table 3) are counterbalanced by the higher flicker noise level.

Data shown in Table 5 also reveal that for the isotope/ solvent combinations that are not affected by any background interference, the LODs obtained with the MWDS are lower (up to a factor of 10) than those obtained with the CS. This situation is different for the isotopes that suffer from spectral interferences. Thus, for ${ }^{52} \mathrm{Cr}^{+}$the LODs obtained using water, $\mathrm{HCl}$ and $\mathrm{HNO}_{3}$ are similar for both the MWDS and the CS. In this case, the higher sensitivities obtained with the MWDS (Table 3 ) are counterbalanced by the higher background signals (Table 4). Using $\mathrm{HClO}_{4}$ and $\mathrm{H}_{2} \mathrm{SO}_{4}$, these LODs are about two times lower with the MWDS than with the CS. For ${ }^{56} \mathrm{Fe}^{+}$the MWDS provides LODs that are a factor of 2 lower than those given by the CS. The LODs obtained for ${ }^{75} \mathrm{As}^{+}$ using $\mathrm{HCl}$ and $\mathrm{HClO}_{4}$ are similar with both systems. For ${ }^{51} \mathrm{~V}^{+}$ and using $\mathrm{HCl}$, the MWDS improves the LOD by a factor of 3, whereas for $\mathrm{HClO}_{4}$ both the MWDS and the CS show similar values of the LOD. Using $\mathrm{H}_{2} \mathrm{SO}_{4}$, the LODs of ${ }^{48} \mathrm{Ti}^{+}$, ${ }^{64} \mathrm{Zn}^{+},{ }^{72} \mathrm{Ge}^{+}$and ${ }^{98} \mathrm{Mo}^{+}$are degraded owing to several sulfurcontaining polyatomic ion interferences (Table 3 ). The MWDS improves these LODs by a factor of 2 , and 40 times in the latter case.

\section{CONCLUSIONS}

From the results shown in this work it is clear that the MWDS is a good choice for low acid concentration sample introduction in ICP-MS even when sulfuric and perchloric acid are used. Nevertheless, in our opinion, these results could be improved. In order to obtain better precision the microwave power control device should be modified so that the applied power could be varied and the design of the spray chamber should be changed. The length and diameter of the present design should be increased or the shape should be optimized in order to reduce the impaction losses of the aerosol against the walls of the spray chamber. In addition, changing the material from which the spray chamber is constructed should lead to a reduction in the contaminant silicon species observed in the backgrounds obtained with the MWDS. Finally, the replacement of the condensers in the cooling step with a more efficient vapour removal system would help to reduce the interferences in ICP-MS.

The authors thank the DGICyT (Spain) for financial support (Project PB95-0693) and Dr. L. Gras for his useful comments.

Table 5 Limits of detection (LODs) obtained with the MWDS and with the conventional sample introduction without desolvation system, CS* $\mathrm{LOD} / \mathrm{ng} 1^{-1}$

\begin{tabular}{|c|c|c|c|c|c|c|c|c|c|c|}
\hline \multirow[b]{2}{*}{ Isotope } & \multicolumn{2}{|c|}{ Water } & \multicolumn{2}{|c|}{$\mathrm{HCl}$} & \multicolumn{2}{|c|}{$\mathrm{HNO}_{3}$} & \multicolumn{2}{|c|}{$\mathrm{HClO}_{4}$} & \multicolumn{2}{|c|}{$\mathrm{H}_{2} \mathrm{SO}_{4}$} \\
\hline & $\mathrm{MWDS}^{\dagger}$ & $\mathrm{CS}^{\ddagger}$ & $\mathrm{MWDS}^{\dagger}$ & $\mathrm{CS}^{\ddagger}$ & $\mathrm{MWDS}^{\dagger}$ & $\mathrm{CS}^{\ddagger}$ & $\mathrm{MWDS}^{\S}$ & $\mathrm{CS}^{\ddagger}$ & $\mathrm{MWDS}^{\S}$ & $\mathrm{CS}^{\ddagger}$ \\
\hline${ }^{48} \mathrm{Ti}^{+}$ & 50 & 120 & 40 & 130 & 40 & 180 & 30 & 130 & 1400 & 2000 \\
\hline${ }^{51} \mathrm{~V}^{+}$ & 7 & 15 & 40 & 100 & 6 & 15 & 200 & 200 & 7 & 18 \\
\hline${ }^{52} \mathrm{Cr}^{+}$ & 80 & 80 & 80 & 90 & 80 & 80 & 50 & 90 & 40 & 90 \\
\hline${ }^{56} \mathrm{Fe}^{+}$ & 2000 & 4000 & 1800 & 4000 & 1900 & 4000 & 2000 & 4000 & 1700 & 4000 \\
\hline${ }^{64} \mathrm{Zn}^{+}$ & 40 & 70 & 80 & 110 & 110 & 140 & 100 & 140 & 600 & 1100 \\
\hline${ }^{72} \mathrm{Ge}^{+}$ & 9 & 20 & 10 & 20 & 10 & 20 & 7 & 30 & 130 & 190 \\
\hline${ }^{75} \mathrm{As}^{+}$ & 20 & 30 & 200 & 200 & 30 & 40 & 200 & 300 & 9 & 50 \\
\hline${ }^{98} \mathrm{Mo}$ & 4 & 19 & 5 & 16 & 4 & 20 & 2 & 20 & 2 & 80 \\
\hline${ }^{103} \mathrm{Rh}^{+}$ & 0.9 & 3 & 0.8 & 4 & 0.8 & 4 & 0.7 & 4 & 0.3 & 4 \\
\hline${ }^{140} \mathrm{Ce}^{+}$ & 2 & 6 & 2 & 6 & 2 & 6 & 1 & 7 & 0.9 & 7 \\
\hline${ }^{208} \mathrm{~Pb}^{+}$ & 7 & 20 & 9 & 30 & 10 & 30 & 4 & 30 & 4 & 30 \\
\hline
\end{tabular}


J. M. thanks the Laboratory of Materials Science (Delft University of Technology) for facilities and the Conselleria de Cultura, Educacio i Ciencia (Generalitat Valenciana, Spain), for a scholarship.

\section{REFERENCES}

1 Evans, E. H., and Giglio, J. J., J. Anal. At. Spectrom., 1993, 8, 1.

2 Niu, H., and Houk, R. S., Spectrochim. Acta, Part B, 1996, 51, 779.

3 Arrowsmith, P., Anal. Chem., 1987, 59, 1437.

4 Boonen, S., Vanhaecke, F., Moens, L., and Dams, R., Spectrochim. Acta, Part B, 1996, 51, 271.

5 Heitkemper, D. T., and Caruso, J. A., Appl. Spectrosc., 1990, 44, 228.

6 Vaughan, M. A., and Horlick, G., Appl. Spectrosc., 1986, 40, 434.

7 Tan, S. H., and Horlick, G., Appl. Spectrosc., 1986, 40, 445.

8 Canals, A., Hernandis, V., Todolí, J. L., and Browner, R. F., Spectrochim. Acta, Part B, 1995, 50, 305.

9 Carre, M., Lebas, K., Marichy, M., Mermet, M., Poussel, E., and Mermet, J. M., Spectrochim. Acta, Part B, 1995, 50, 271.

10 Jakubowski, N., Feldmann, I., and Stuewer, D., J. Anal. At. Spectrom., 1993, 8, 69 .

11 van Veen, E. H., Bosch, S., and de Loos-Vollebregt, M. T. C., Spectrochim. Acta, Part B, 1994, 49, 1347.

12 van Veen, E. H., Bosch, S., and de Loos-Vollebregt, M. T. C., Spectrochim. Acta, Part B, 1996, 51, 591.

13 Lam, J. W. H., and Horlick, G., Spectrochim. Acta, Part B, 1990, 45, 1313.

14 Castillano, T. M., Giglio, J. J., Evans, E. H., and Caruso, J. A., J. Anal. At. Spectrom., 1997, 12, 383.

15 Olson, L. K., and Caruso, J. A., Spectrochim. Acta, Part B, 1994, 49, 7.

16 Tittes, W., Jakubowski, N., Stuwer, D., Tolg, G., and Broekaert, J. A. C., J. Anal. At. Spectrom., 1994, 9, 1015.

17 Vanhaecke, F., Moens, L., Dams, R., Papadakis, I., and Taylor, P., Anal. Chem., 1997, 69, 268.

18 Hieftje, G. M., Myers, D. P., Li, G., Mahoney, P. P., Burgoyne, T. W., Ray, S. J., and Guzowski, J. P., J. Anal. At. Spectrom., 1997, 12, 287.

19 Pollmann, D., Pilger, C., Hergenroder, R., Leis, F., Tschopel, P., and Broekaert, J. A. C., Spectrochim. Acta, Part B, 1994, 49, 683.

20 Hernandis, V., Todolí, J. L., Canals, A., and Sala, J. V., Spectrochim. Acta, Part B, 1995, 50, 985.

21 Alves, L. C., Wiederin, D. R., and Houk, R. S., Anal. Chem., 1992, 64, 1164.

22 Jakubowski, N., Feldmann, I., and Stuewer, D., Spectrochim. Acta, Part B, 1992, 47, 107.

23 Gustavsson, A., Spectrochim. Acta,, Part B, 1988, 43, 917.

24 Wiederin, D. R., Houk, R. S., Winge, R. K., and D'Silva, A. P., Anal. Chem., 1990, 62, 1155.
25 Brenner, I. B., Zander, A., Plantz, M., and Zhu, J., J. Anal. At. Spectrom., 1997, 12, 273.

26 Tao, H., and Miyazaki, A., J. Anal. At. Spectrom., 1995, 10, 1.

27 Alves, L. C., Allen, A. L., and Houk, R. S., Anal. Chem., 1993, 65, 2468.

28 Tarr, M. A., Zhu, G., and Browner, R. F., J. Anal. At. Spectrom., $1992,7,813$

29 Goulden, P. D., and Anthony, D. H. J., Anal. Chem., 1982, 54, 1678.

30 Hell, A., Ulrich, W. F., Shifrin, N., and Ramirez-Muñoz, J., Appl. Opt., 1968, 7, 1317.

31 Eastgate, A., and Vogel, W., Patent number WO 92/02282, 1992.

32 Eastgate, A. R., Fry, R. C., and Gower, G. H., J. Anal. At. Spectrom., 1993, 8, 305.

33 Gunther, D., Cousin, H., Magyar, B., and Leopold, I., J. Anal. At. Spectrom., 1997, 12, 165.

34 Hernandis, V., Canals, A., Mora, J., and Gras, L., Patent number P9500810, 1995.

35 Gras, L., Mora, J., Todolí, J. L., Canals, A., and Hernandis, V., Spectrochim. Acta, Part B, 1997, 52, 1201.

36 Gras, L., Mora, J., Todolí, J. L., Canals, A., and Hernandis, V., Spectrochim. Acta, Part B submitted.

37 Canals, A., Hernandis, V., and Browner, R. F., Spectrochim. Acta, Part B, 1990, 45, 591.

38 Hinds, W. C., Aerosol Technology: Properties, Behaviour and Measurement of Airborne Particles, Wiley, New York, 1982, ch. 13, p. 249.

39 Pan, C., Zhu, G., and Browner, R. F., J. Anal. At. Spectrom., 1990, 5, 537.

40 Vanhaecke, F., Dams, R., and Vandecasteele, C., J. Anal. At. Spectrom., 1993, 8, 433.

41 Vanhaecke, F., van Holderbeke, M., Moens, L., and Dams, R., J. Anal. At. Spectrom., 1996, 11, 543.

42 French, J. B., Etkin, B., and Jong, R., Anal. Chem., 1994, 66, 685.

43 Introduction to Microwave Sample Preparation. Theory and Practice, ed. Kingston, H. M., and Jassie, L. B., American Chemical Society, Washington, DC, 1988.

44 Gras, L., PhD Thesis, University of Alicante, 1997.

45 Bordera, L., Todolí, J. L., Mora, J., Canals, A., and Hernandis, V., Anal. Chem., 1997, 69, 3578.

46 Hinds, W. C., Aerosol Technology: Properties, Behaviour and Measurement of Airborne Particles, Wiley, New York, 1982, ch. 15 , p. 284.

47 Loeb, L. B., Static Electrification, Springer-Verlag, Berlin, 1958.

48 Boumans, P. W. J. M., Spectrochim. Acta, Part B, 1991, 46, 431.

49 Boumans, P. W. J. M., Spectrochim. Acta, Part B, 1991, 46, 917.

50 Boumans, P. W. J. M., J. Anal. At. Spectrom., 1993, 8, 767.

Paper $7 / 06833 F$

Received September 22, 1997 Accepted November 21, 1997 